\title{
アルミナ顆粒粉の段付カップへの加圧流動成形
}

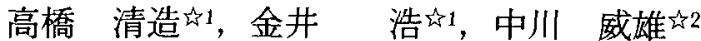 \\ 社 日本大学生産工学部, 干275 習志野市泉町1-2-1. \\ 的 東京大学生産技術研究所, 干106 港区六本木7-22-1.
}

\section{Stepped Cup Forming from Alumina Granula by Press Powder Flow Compaction}

\author{
Seizo Takahashi ${ }^{\text {r }} 1$, Hiroshi Kanai ${ }^{2}$ and Takeo Nakagawa \\ t1 Col. Ind. Tech., Nihon University, 1-2-1 Izumi-cho, Narashino 275. \\ t2 Inst. Ind. Sci., University of Tokyo, 7-22-1 Roppongi Minato-ku, Tokyo 106.
}

Received June 16, 1993

Stepped cup compact were formed by a uniaxial hydraulic press from alumina granule with 3wt\% PVA (Polyvinyl Alchohol) after admixing liquid paraffin, and density distribution in green compact was measured. The difference in local density of green compact could be reduced by press flow compaction, in spite of that the decreasing was impossible by dry compaction. It was confirmed that when green compact was formed from the granule with the sufficient flowability by admixed liquid paraffin, the densified powder flowed from the bottom to the cup wall during compaction.

The relative density of sintered compact was $92 \%$, and diameter shrank by $15 \%$ in average. In dry compaction, the difference in diameter of the sintered compact is large, but in pressurized flow compaction with 10wt\% liquid paraffin the shrinkage was almost uniform along the cup wall.

\section{1 はじめに}

セラミックス粉末から粉末治金法で機械部品を製造 する際，粉末の焼結性が良好である場合には，焼結に 支障のないある程度以上の成形体密度と内部の密度分 布が少ないことが要求される. 成形時に生ずる成形体 内部の密度分布は成形体へのクラック発生の原因とな り易く，また焼結時の寸法収維にともなうクラック発 生や寸法精度の悪化をもたらす. 加圧流動成形法は粉
末に液状バインタを添加して成形時の粉末に流動性を 付加することから, 成形体の高密度化と成形体各部の 密度差を娍少できる. 本成形法の特長を活かし，これ までセラミックス粉末についてはりフトフェライト顆 粒粉 ${ }^{1)}$ およひアルミナ顆粒粉 ${ }^{2}$ 'を成形し，良好な結果 が得られている.

本報はアルミナ顆粒粉に流動パラフィンを添加後, カップの肉厚が変化する段付カップに成形し, 成形体 内部の密度分布の変化を中心に本成形法の特長を検討 
した.また焼結体の直径を測定し，瑨結にともなう直 径の収摍から，本成形法の特長を確かめた。

\section{2 実験方法}

成形に使用したアルミナ顆粒粉（高木産業製）は 3 wt\%PVAを含み, スプレードライで造粒されており，平 均粒径が約 $100 \mu$ 故ある ${ }^{2}$. 顆粒粉へは流動パラフィ ンを最大10wt\% まで添加し, Fig.1 に示す段付カップ を成形した. 成形は $16 \mathrm{~g}$ の粉末を単軸油压ブレスで压 粉し, 成形圧は 984Paから294MPa, 成形方式はフロー ティングタイ法とした。 成形体の評価は外観の観察, 成形体密度の測定を行い, さらに成形体をカップ底, 壁一 1 , 壁一 2 に 3 分割後, 各部の密度を測定し, 成 形体内部の密度分布を求めた. $350^{\circ} \mathrm{C} \cdot 2 \mathrm{hr}$ の脱バイン 多後, $1550^{\circ} \mathrm{C} \cdot 3 \mathrm{hr}$ の焼結を行い, 焼結体の密度, 直径 を測定し，焼結にともなう寸法の収縮について考察し た.

\section{3 実験結果およひ考察}

Table 1 は成形体の外観を観察した結果を示す. 成

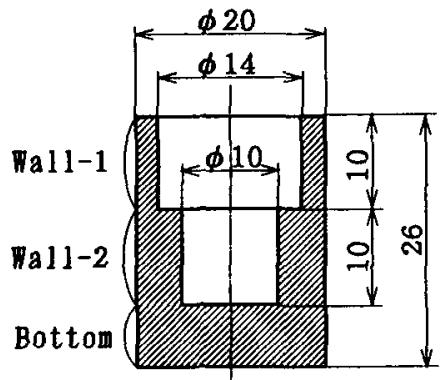

Fig.1 Dimension of formed green compact. (mo)

Table 1 Evaluation of formability and defect of green compact by changing in compacting pressure and content of. liquid paraffin.

\begin{tabular}{|c|c|c|c|c|c|}
\hline \multirow{2}{*}{$\begin{array}{c}\text { Compacting } \\
\text { pressure } \\
(\mathrm{MPa})\end{array}$} & \multicolumn{5}{|c|}{ Content of liquid paraffin (wt\%) } \\
\cline { 2 - 6 } & 0 & 2.5 & 5.0 & 7.5 & 10.0 \\
\hline 98 & $\bigcirc$ & $\bigcirc$ & $\bigcirc$ & $\bigcirc$ & $\bigcirc^{*}$ \\
\hline 147 & $\bigcirc$ & $\bigcirc$ & $\bigcirc$ & $\bigcirc$ & $\bigcirc^{*}$ \\
\hline 196 & $\bigcirc$ & $\bigcirc$ & $\bigcirc$ & $\triangle$ & $\triangle^{*}$ \\
\hline 294 & $\bigcirc$ & $\bigcirc$ & $\bigcirc$ & $\triangle^{*}$ & $\triangle^{*}$ \\
\hline
\end{tabular}

(D): Good green compact formed

$\bigcirc$ :Cracking at cup wall

$\triangle$ :Cracking at cup wall and bottom

*:Blistering at botttom end

\#:Exuding liquid paraffin from green compact
形压が高い場合，成形体にはクラックが発生し，流動 パラフィンの添加量が多いと成形体から流動パラフィ ンのしみ出す等の欠陌か起こる.

Fig.2 は成形体密度と流動パラフィンの添加量の関 係を示す. 流動パラフィンの添加にともない成形体密 度は上昇し，成形压によって成形体密度が最高値とな る流動パラフィンの添加量は変化するが，それ以上の 添加量では密度は低下する．多量の流動パラフィンを 添加した場合に成形体密度が低下する原因は，圧粉の 過程で減少した成形体内の気孔に流動パラフィンが充 渵し, 流動パラフィンのしみ出しが発生し, 成形体内 は流動パラフインの静水圧状態にあり，成形体密度の 上昇を抑制するためと考えられる。

成形体を 3 分割して測定した成形体内部の密度分布 をFig.3 からFig.7 に示す. Fig.3 は流動パラフイン を添加しない乾式成形の結果を示し，乾式成形では高 密度なカップ底の密度と，低密度なカップ壁の密度と の密度差は成形圧を上昇させても容易に解消されない。 Fig.4 からFig.7 は各成形圧における成形体各部の密 度と流動パラフィンの添加量との関係を示す，成形圧 か 98MPaの場合 (Fig.4)，流動パラフィンの添加量 10wt\%で内部の密度差は堿少した. 成形圧が 147MPaで は（Fig.5），流動パラフィンの添加量が 5 wt\%以下に おいて, 成形体内の各部の密度は流動パラフインの添 加量に比例して上昇するが，成形体内部での密度差は 解消されない，流動パラフインの添加量が7.5wt\%では， カップ底の密度は添加量5wt\%から低下し，壁ー 1 の密 度は急上昇する．その結果，成形体内部の密度差は著

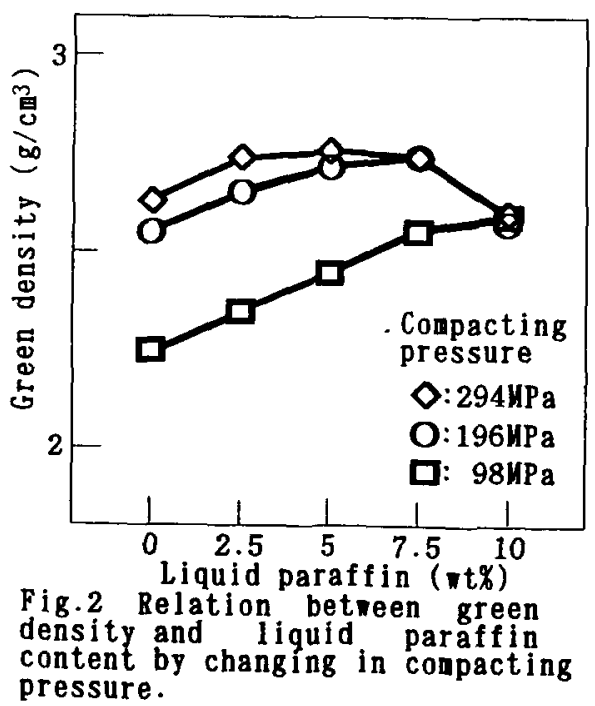


しく減少した。成形圧が 294MPaの場合（Fig.7），流 動パラフィンの添加量が少ない2.5wt\%でカップ底の密 度は最高值となり，それ以上の流動パラフィン添加で はカップ底の密度は低下する，一方，壁－10密度は 流動パラフィンの添加によりゆるやか上昇し, 流動 パラフィンの添加量7.5 wt\%以上では, 成形体内部の密 度差は少ない。

つぎに，粉末の圧粉過程を推定するために，オート グラフによって成形王とパンチストロークの線図を測 定し，Fig.8に示す．圧粉速度は2mm/minとした。流動 パラフィンの添加の有無で比較すると，成形圧が上昇 し始めるまでのパンチストロークが異なっている. 成 形压の値で圧粉工程の終りが決められているため, パ ンチストロークの長い場合, カップ底の厚さは薄くな る. 流動パラフインの添加によって所定の成形圧まで

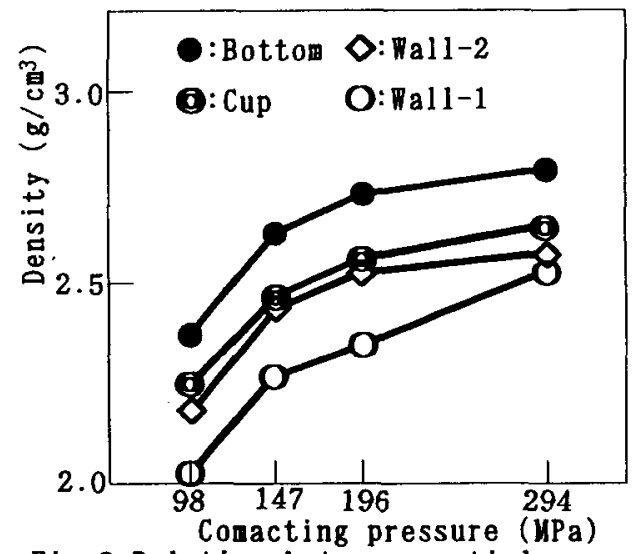

Fig. 3 Relation between partial density and conpacting pressure. ( $L$ iquid paraffin : 0 )

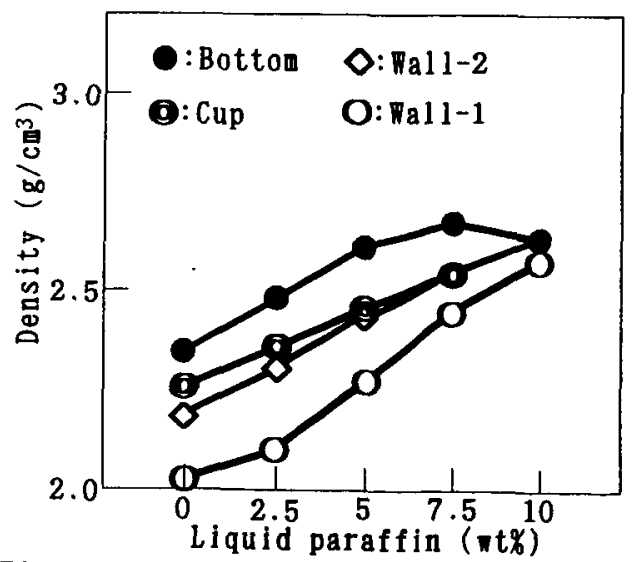

Fig. 4 Relation between partial density and liquid paraffin content. (Conpacting pressure : $98 \mathrm{UPa}$ )

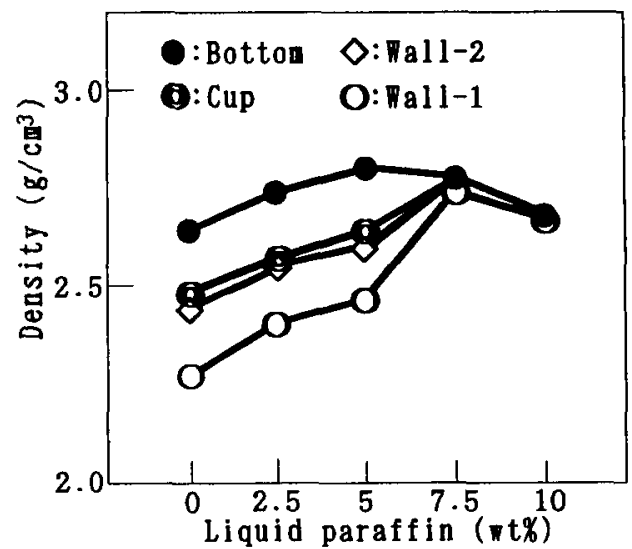

Fig. 5 Relation between partial density and liquid paraffin content.

(Compacting pressure : 147MPa)

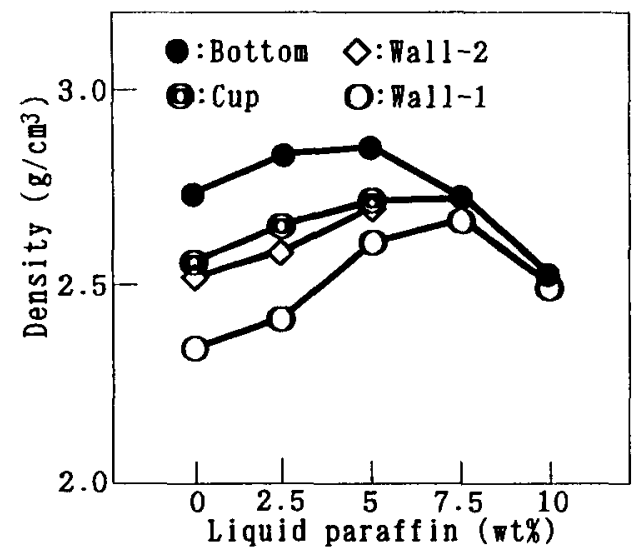

Fig.6 Relation between partial density and liquid paraffin content.

(Compacting pressure : 196 MPa)

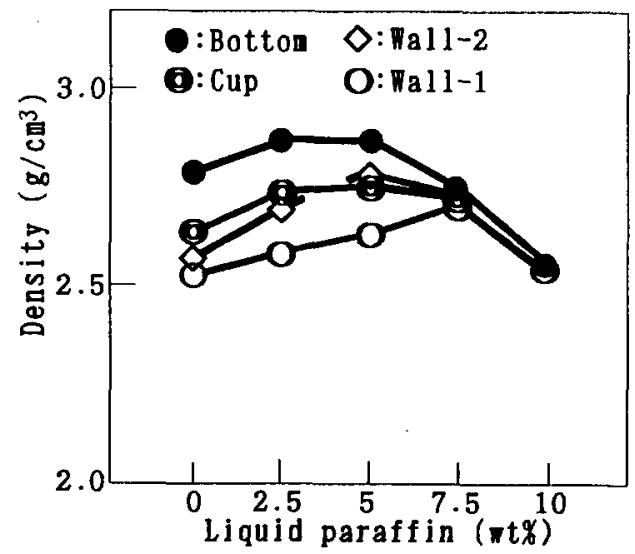

Fig. 7 Relation between partial density and 1 iquid paraffin content.

(Conpacting pressure : $294 \mathrm{MPa}$ ) 


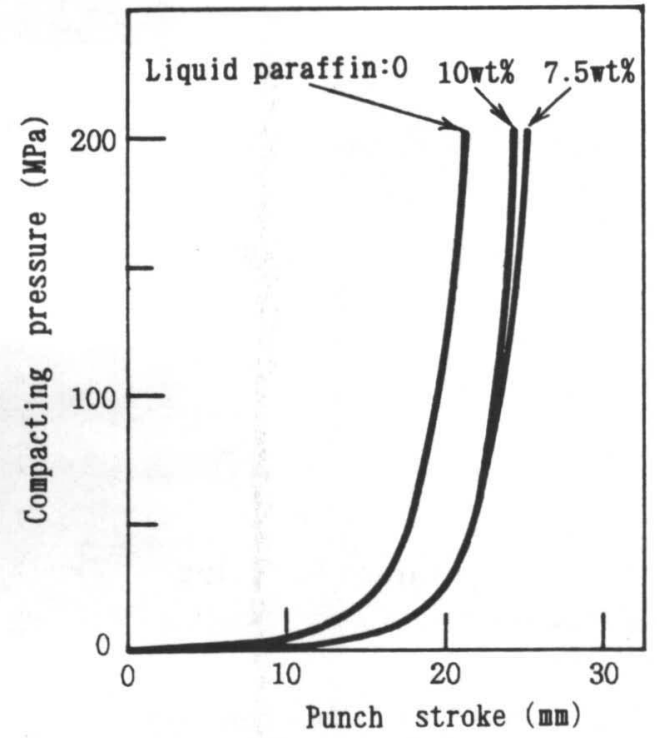

Fig.8 Diagram of compacting pressure-punch stroke by changing in content of liquid paraffin.

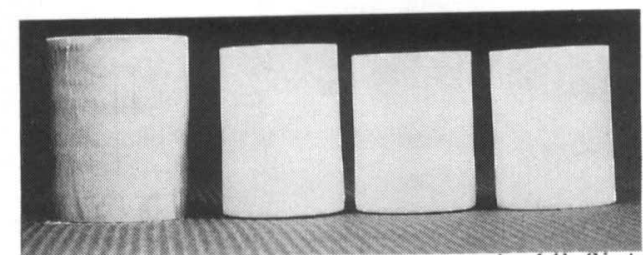
(a) Green
(b) Sintered(c) Sintered
(d) Sintered compact compact $L P: 0$
LP:7.5wt\%
compact LP:0 Photo.1 External appearance of green compact and sintered compact by changing in Sintering : $1550^{\circ} \mathrm{C} * 3 \mathrm{hr}$ )

のパンチストロークは長く, カップ底の厚さは薄くな つた. 粉末の成形過程においてカップ底に存在した粉 末はカップ壁に流動し, カップ底の厚さは減少し, 成 形体は高密度かつ均一密度になると考えられる.

つぎに焼結体の外観をPhoto.1，焼結体の直径を測 定した結果はFig.9 に示す. 成形圧が147MPaの例であ り, 烊結体の直径は成形体の直径 $20 \mathrm{~mm}$ から約 $17 \mathrm{~mm}$ まで 収縮し, 収縮事は長さで約 $15 \%$ となった. 焼結体の直 径はカップ底が大きく, カップの上縁が小さい. それ は成形体においてカップ底が高密度であり, カップ上 縁が低密度であったことによる．流動パラフィンの添 加量で比較すると, 添加なしでは直径の差は大きいが, とくに流動パラフィンの添加量が 10wt\%では直径の差 は著しく小さい. すなわち, 焼結体の寸法精度は高く なった. また焼結体の密度は相対密度で92\%であった.

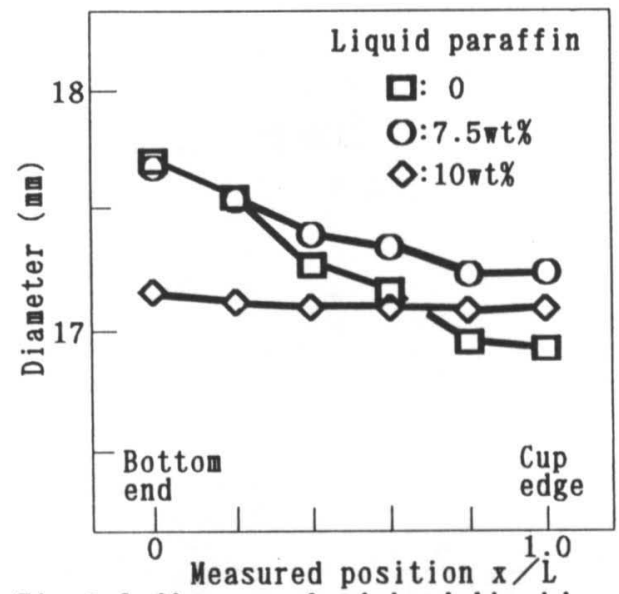

Fig. 9 Influence of admixed liquid paraffin content on diameter of sintered compact. (Compacting pressure : $147 \mathrm{KPa}$, Sintering: $155^{\circ} \mathrm{C} * 3 \mathrm{hr}$ )

\section{4 おわりに}

アルミナ顆粒粉から段付カップを加圧流動成形法に よって成形し, 本成形法の特長と得られた焼結体の寸 法精度を検討した結果をまとめると以下になった。

1）流動パラフィンの添加により, 成形体密度は上昇 し, 流動パラフィンの適量添加において最高値を 示した.

2) 乾式成形法と比較して, 本成形法によって成形体 各部の密度差は減少した. 流動パラフィンの添加 によって生じた成形過程での粉末流動は薄肉な壁 の密度を上昇させ, 結果として成形体内部の密度 差は減少する.

3）焼結体の寸法精度は成形体内部の密度分布に関係 し, 密度差の少ない成形体からの焼結体は高精度 となった。

\section{謝 辞}

本研究を行うにあたり, 東大生研中川研究室の安斎 正博博士 (現理化学研究所) および野口裕之技官から 適宜助言を戴いたことに深謝致します．またアルミナ 顆粒粉の提供を戴いた高木産業侏)の関係各位に感謝致 します.

\section{文 献}

1)高橋清造, 中川威雄 : 粉体および粉末治金, 39 (1992) 1005.

2)高橋清造, 中川威雄 : 粉体および粉末治金, 40 (1993) 426. 